\title{
APONTAMENTOS SOBRE A PARTICIPAÇÃO DEMOCRÁTICA NAS AUDIÊNCIAS PÚBLICAS DO LICENCIAMENTO AMBIENTAL
}

\section{Kamylla da Silva Bezerra ${ }^{1}$ Eduardo Garcia Ribeiro Lopes Domingues ${ }^{2}$}

Resumo: O presente artigo tem por objetivo analisar empiricamente a participação da sociedade nas audiências públicas realizadas no âmbito do licenciamento ambiental do Estado do Rio de Janeiro. Para tanto, foram utilizados o levantamento e análise documental em abordagem quantitativa enquanto instrumentos metodológicos. Foi possível observar que o Estado do Rio de Janeiro vem empreendendo esforços para promover maior participação social no processo de licenciamento ambiental, já que os dados demonstram uma ativa participação da sociedade nos debates travados durante as audiências públicas.

Palavras-chave: democratização da administração pública; participação popular; sociambientalismo

\section{POINTS ON DEMOCRATIC PARTICIPATION IN THE PUBLIC PUBLIC HEARINGS OF ENVIRONMENTAL LICENSE}

Abstract: The purpose of this paper is to analyze empirically the participation of society in the public hearings held in the scope of the environmental licensing of the State of Rio de Janeiro. For that, the documentary survey and analysis was used in quantitative approach as methodological instruments. It was possible to observe that the State of Rio de Janeiro has been making efforts to promote greater social participation in the environmental licensing process, and the data showed an active participation of society in the debates held during the public hearings.

Key-words: democratization of public administration; popular participation; sustainability

\section{INTRODUÇÃO}

A teoria jurídica tem demonstrado a necessidade de compreensão analítica a partir da abordagem complexa frente aos novos desafios e conflitos que envolvem as questões ambientais. Considerando ser essa uma temática em ascensão no debate contemporâneo, posto que já é amplamente aceito que os recursos naturais são escassos e, assim, precisam ser

\footnotetext{
${ }^{1}$ Advogada com Bacharelado em Direito pela Universidade Estadual da Paraíba (2014), Mestre (2018) em Direito e Políticas Públicas pela Universidade Federal do Estado do Rio de Janeiro (UNIRIO).

${ }^{2}$ Advogado com Bacharelado em Direito pela Universidade Candido Mendes (1999), Mestre (2003) e Doutor (2009) em Direito da Cidade pela Universidade do Estado do Rio de Janeiro (UERJ). Professor da Graduação em Direito e do Mestrado em Direito e Políticas Públicas da Universidade Federal do Estado do Rio de Janeiro (UNIRIO). Professor do Curso de Direito das Faculdades Integradas Hélio Alonso (FACHA).
} 
pensados dentro de uma abordagem sustentável, a temática do direito ambiental vem sendo discutida dentro da teoria do desenvolvimento sustentável.

A Constituição Federal brasileira de 1988, também conhecida como constituição verde, repartiu a responsabilidade de promoção do desenvolvimento sustentável entre o Estado e a sociedade. Entretanto, o mero compartilhamento formal dessa responsabilidade, por si só, não assegura que os resultados desejados sejam alcançados. Assim, surgem diversas problemáticas relacionadas a questão da efetividade da legislação brasileira relativa ao meio ambiente, constituindo desafios a serem enfrentados pela sociedade.

Outrossim, no centro das ideias de promoção das instituições políticas, da cultura democrática e das questões ambientais, está o processo administrativo brasileiro quando relacionado à defesa da democratização da Administração Pública. Giannini (1986) indica a participação popular na esfera administrativa como uma das características da Administração pública contemporânea. Di Pietro (2018), por sua vez, afirma que a participação na Administração é uma “característica essencial do Estado de Direito Democrático, porque ela aproxima mais o particular da Administração, diminuindo as barreiras entre sociedade e Estado".

Na visualização de uma autêntica teoria do processo administrativo e na busca pela democratização da Administração Pública, a audiência pública estará inserida como um instrumento de participação do cidadão na esfera administrativa. Moreira Neto (1992) define que a audiência pública é:

\footnotetext{
"Um instrumento de participação administrativa aberta a indivíduos e grupos sociais determinados, visando à legitimidade da ação administrativa, formalmente disciplinada em lei, pela qual se exerce o direito de expor tendências, preferências e opções que possam conduzir o Poder Público a uma decisão de maior aceitação consensual”. (MOREIRA NETO, 1992, pp.)
}

No que tange ao relacionamento entre às questões ambientais e democráticas, é factível que, conforme preleciona Acselrad \& Leroy (1999), a construção de um Brasil com desenvolvimento sustentável exigirá justamente o aprofundamento da democracia. Além disso, Fiorillo (2016) destaca que uma vida saudável reclama a satisfação de um dos fundamentos democráticos da nossa Constituição Federal, qual seja, a dignidade da pessoa humana, que somente poderá ser garantida caso seja viabilizado o mínimo existencial com o qual o ser humano possa sobreviver com dignidade. Assim, é oportuna a afirmativa de 
Oliveira (1997), no sentido de que a tutela do meio ambiente, bem de uso comum do povo, há de ser levada a efeito com a participação da comunidade, sendo dever do Estado a promoção da educação ambiental e da conscientização pública para tal fim, identificando no caráter pedagógico das audiências públicas uma real oportunidade para tanto.

Posto isto, este trabalho pretende analisar parte do processo administrativo de licenciamento ambiental, mais especificamente as questões relacionadas à audiência pública e à participação popular. Para tanto, a metodologia utilizada foi a de levantamento bibliográfico e documental, assim como a análise de dados e conteúdo. Assim, foi realizada análise empírica da audiência pública no processo de licenciamento ambiental com o objetivo de demonstrar a dinâmica da participação nos debates travados nas audiências concretizadas no âmbito de licenciamento ambiental no estado do Rio de Janeiro durante o lapso temporal de 2013 a 2016. Para tanto, foram destacadas a distribuição quantitativa das manifestações dos participantes das audiências públicas e a distribuição dos temas abordados pela sociedade, com a finalidade de avaliar a participação da sociedade.

\section{AS AUdiênCIAS PÚblicas E A PROMOÇão dA PARTICIPAÇÃo DEMOCRÁTICA NO LICENCIAMENTO AMBIENTAL}

Um dos aspectos mais inovadores da Constituição Federal brasileira de 1988 foi o estabelecimento e ampliação de diversos canais de interlocução entre autoridades públicas e cidadãos através, por exemplo, da instituição da participação de trabalhadores e empregados nos colegiados dos órgãos públicos em que seus interesses profissionais ou previdenciários sejam objeto de discussão (art. 10, CF); da iniciativa popular no processo legislativo (art. 27, $\S 4^{\circ}$; art. 29, XIII e art. 61, §21, CF); da cooperação das associações representativas no planejamento municipal (art. 29, XII, CF); e a participação direta dos contribuintes na fiscalização das contas municipais (art. 31, $\S 3^{\circ}, \mathrm{CF}$ ).

A audiência pública, apesar de ter restado ausente em previsão expressa na Constituição Federal de 1988, surgiu em nosso ordenamento pátrio antes mesmo da concretização do processo de redemocratização, ainda em 1986. Através da Resolução do Conselho Nacional do Meio Ambiente - Conama no 1, de 23 de janeiro de 1986, buscava-se utilizar a Audiência Pública quando tivesse por finalidade "expor aos interessados o conteúdo do produto de análise do Relatório de Impacto Ambiental - RIMA, dirimindo dúvidas e 
recolhendo dos presentes as críticas e sugestões a respeito”. Já em 1987, a Audiência Pública passou a ter papel central no âmbito do Poder Legislativo por meio da Assembleia Constituinte quando, de acordo com Backes, Azevedo \& Araújo (2009, p. 14):

"As 4 Subcomissões da Assembleia Nacional Constituinte, instaladas em 7 de abril de 1987,
iniciaram as reuniões de audiência pública a partir de do mesmo mês e começaram a discutir
seus relatórios em meados do mês de maio. Portanto, em torno de apenas três semanas, foram
realizadas as cerca de 200 reuniões, sendo ouvidos, simultaneamente, os mais diferentes
setores da sociedade brasileira. Ao longo desses dias intensos, quase 900 pessoas -
representantes de organizações da sociedade civil, acadêmicos, órgãos governamentais, juristas
e outros - ocuparam todas as tribunas do Congresso, apresentaram centenas de propostas,
polemizaram em torno dos principais temas em discussão, debateram com os constituintes,
demarcaram campos e objetos de disputa política. O Parlamento foi tomado por delegações de
todo o Brasil, abrindo espaço para múltiplas vozes".

Atualmente, podemos destacar a consolidação da Audiência Pública enquanto instrumento de abertura dialógica entre o Poder Legislativo e os cidadãos, ao mesmo tempo em que observamos o processo de consolidação desse instrumento no âmbito do Poder Judiciário, através das Audiências Públicas realizadas pelo Supremo Tribunal Federal e da nova e mais ampla previsão trazida pelo Novo Código de Processo Civil. É no âmbito do Poder Administrativo, porém, que este instrumento tem apresentado atraso de evolução prática, em contraponto a previsão de que "o Direito Administrativo contemporâneo tende ao abandono da vertente autoritária para valorizar a participação de seus destinatários finais quanto à formação da conduta administrativa” (FERRAZ, 2006, p. 263).

Apesar de estarmos tratando de um instrumento que é utilizado tanto no âmbito da atividade legislativa quanto judiciária e administrativa, é objetivo deste trabalho a análise da utilização deste instrumento no âmbito da atividade administrativa e, em especial, nos processos de licenciamento ambiental. Nesse sentido, é interessante avaliação do respeitável administrativista Moreira Neto (2007), segundo o qual Audiência Pública é um instituto de participação administrativa aberta a indivíduos e grupos sociais determinados e que visa à legitimidade da ação administrativa. Alonso \& Costa (2004), por sua vez, incluem as Audiências Públicas no rol de mecanismos brasileiros de governança, caracterizadas em reuniões públicas que buscam expandir a participação popular na discussão pública. Oliveira (2010), salientando o caráter pedagógico da Audiência Pública, posto que estabelece a oportunidade de conscientização e educação da população, também as inclui no rol de mecanismos ou instrumentos de participação dos cidadãos na esfera administrativa, ao lado da 
coleta de opinião, debates, consulta e colegiado público. Já de acordo com Bim (2014), tratase de um instrumento da cidadania ampla, que prescinde da capacidade eleitoral e que incorpora o cidadão à política, promovendo uma participação efetiva e influente no rumo das decisões estatais, ainda que de forma não vinculante. Para fins deste trabalho aceitamos como mais completo o conceito proposto por Melo (2016, p. 41) sobre o referido instituto participativo:

“Audiência pública na função administrativa é um processo administrativo cujo objetivo é ouvir segmentos da sociedade antes da formulação de uma política pública ou da tomada de uma decisão e, com isso, contribuir para: (i) a legitimidade da atuação estatal no exercício da função administrativa; (ii) a construção conjunta da melhor decisão possível; (iii) o fortalecimento da autonomia pública dos cidadãos, por meio da participação democrática no processo de formação da decisão e vontade; e (iv) aperfeiçoamento da transparência e do controle social da ação estatal".

Existe corrente que entende que as audiências púbicas derivam da perspectiva coletiva do princípio anglo-saxão de ser ouvido antes de uma decisão que possa afetar direitos ou interesses coletivos (MOREIRA NETO, 2006). Oliveira (2010) compreende que será por meio da realização de audiências públicas que será garantido o direito fundamental do cidadão de ser ouvido e de poder opinar a respeito de assuntos que interessem à coletividade, sacando da Constituição Federal o caminho que sinaliza a colaboração entre Administração e administrado. Melo (2016, p. 83) defende que o instrumento em analise possui fundamento no Texto Constitucional brasileiro, que "lança as bases de um Estado Democrático de Direito fundado na democracia participativa, na soberania popular e no princípio participativo", assim, a legislação infraconstitucional estaria a cargo apenas de prever as situações em que seria possível a convocação de audiência pública em determinados assuntos que necessitassem da abertura democrática.

É mais acertada a defesa de Bim (2014) quando nos ensina que não há no ordenamento constitucional brasileiro a previsão de um direito à audiência pública em face de uma decisão que possa afetar a coletividade, excetuando alguns casos que envolvam agências reguladoras. O fundamento jurídico da Audiência Pública não é constitucional, mas infraconstitucional, já que deverá estar relacionada à prévia existência de lei em sentido estrito que preveja a possibilidade ou imposição de sua realização. Dessa forma, expressa previsão legal em norma infraconstitucional da realização da audiência pública poderá até gerar direito subjetivo aos cidadãos nos casos em que há obrigatoriedade. No mesmo sentido, 
Silva (2009, p. 55), ao reconhecer a importância do instrumento para participação popular, nega seu caráter de direito fundamental constitucionalmente assegurado, ao esclarecer que ela é "um direito do administrado quando assim previsto em lei lato sensu". É correto, assim, que o fundamento das audiências públicas é legal e infraconstitucional, não podendo ser sacado diretamente da Constituição Federal. Devemos lembrar, igualmente, que não se podedizer que estamos diante de um direito cuja existência esteja relacionada exclusivamente aos princípios da ampla defesa ou ao contraditório quando da sua realização, mas sim de um direito baseado em mera previsão legal.

Ademais, quanto à função da Audiência Pública no processo de licenciamento ambiental, de acordo com Domingos, Lanchotti \& Diz (2016), esta estaria a cargo de garantir o exercício do direito constitucional de acesso à informação. Moreira (2011) ensina que a audiência pública surgiu no Direito brasileiro como um instrumento de accountability cuja função é informar os interessados e promover a discussão do relatório sobre impactos ambientais, de acordo como previsto na Resolução Conama nº1, que fixou os objetivos das diretrizes para o uso e implementação da avaliação do impacto ambiental como um dos instrumentos da Política Nacional do Meio Ambiente, trazendo em seu art. 11, §2º disposição sobre o prazo para manifestação e comentários feitos por órgãos públicos e demais interessados e facultando a realização da Audiência Pública para transmissão de informações sobre impactos ambientais. Entretanto, Bim (2014, p. 182) esclarece que é justamente na área ambiental que se encontra o maior distanciamento das Audiências Públicas de sua real finalidade, afirmando que:

"Maria Augusta Ferreira, com o apoio da doutrina portuguesa, aduz que a finalidade da audiência pública é a participação do público, não a mera informação, pois esta já é objeto da publicidade do processo".

Entretanto, não há dúvida que a audiência pública reforça a divulgação de informações do processo administrativo. Ainda que esta não seja sua função principal, a audiência desempenha importante papel informativo, já que promove um fluxo de informações ambivalente, municiando a população com informações relevantes sobre o possível ato estatal, bem como a autoridade que tomará a decisão. Machado (2016, p. 259) aponta para tal ambivalência no fluxo informacional da audiência pública: "há uma dupla caminhada na 
audiência: o órgão público presta informações ao público e o público presta informações à Administração Pública”.

Em regra, a função informativa da audiência pública possui natureza endógena, devendo ser aplicada apenas em seu âmbito interno. Entretanto, quando existe lei prevendo que a audiência pública servirá para informar, sua razão de existir também será a publicidade. Quando possuir função informativa exógena, esta será satisfeita através da publicidade da audiência pública e documentos pertinentes à mesma, além de ser viabilizada pela própria audiência pública (BIM, 2014, p. 73).

O princípio da publicidade não deverá ser sacado como suficiente para deflagrar ou criar uma audiência pública, posto que a partir do regime geral das audiências públicas (Lei 9.784/1999, art. 32), essa função informativa exógena não existe, devendo haver lei em sentido estrito que especifique esta função. Assim, não existe audiência pública para informar, exceto se houver lei nesse sentido, excepcionando o regime geral e extrapolando a verdadeira finalidade das audiências.

Outrossim, o destaque dado ao aspecto informativo da audiência pública pertence à sociologia das audiências e não à sua finalidade jurídica. Caso a audiência pública tivesse como finalidade a publicidade dos atos administrativos, não teria sentido a necessidade prévia de divulgação de documentos antes da realização da audiência. Essa divulgação seria desnecessária, já que as informações seriam divulgadas na própria audiência.

A função informativa é mencionada muitas vezes enquanto uma necessidade para possibilitar a participação informada dos cidadãos, não sendo um fim em si mesma. Assim, para evitar que a audiência seja uma reunião sem participação, ela também deverá ter por objetivo informar, mas esse não é seu pressuposto. Assim, internamente a informação é efetivada na fase expositiva da audiência, precedida pela fase consultiva. (BIM, 2014; BIM, 2016).

A divulgação prévia da informação pertinente à audiência pública é necessária, além de se exigir linguagem acessível aos leigos interessados. A divulgação prévia das informações poderá ser realizada através de diversos meios pela Administração Pública, seja através do 
Diário Oficial; nas repartições do próprio órgão, por meio de pedidos de acesso à informação; ou até mesmo pela internet, no site oficial do órgão.

A partir da convocação da audiência pública deverá ser especificado um prazo que servirá para que os interessados busquem à obtenção de documentos (relatórios, estudos, etc.) vinculados ao tema da audiência, mediante o direito de acesso à informação estatal. Assim, é recomendável que o prazo de convocação seja maior do que o necessário à obtenção dessas informações. não imposição obrigatória da realização da audiência pública”.

Sobre a convocação da audiência pública, a Lei 9.784/1999 deixou de prever um prazo mínimo, fazendo com que as demais legislações sofram de grande variação, o que gera certa insegurança jurídica. Bim (2014) afirma que quando não existir de prazo a ser seguido na legislação, seria razoável a exigência de 10 (dez) dias, tanto pela logística do comparecimento quanto pela possibilidade de participação informada.

A Lei 10.650/2003, que regula a garantia da prestação de informações relativas ao ambiente no Brasil, poderá ser utilizada para promover algum efeito sobre a pré-divulgação de informações para audiência pública em licenciamento ambiental, sobretudo no que diz respeito ao pedido dos interessados em ter acesso a documentação pertinente ao processo decisório ambiental.

Outrossim, quando a audiência pública é realizada pelo IBAMA, a IN 184/08 preceitua que o RIMA deverá estar disponível no site oficial do órgão e nos locais indicados na publicação, promovendo um modelo de divulgação prévia de informações que amplifica a publicidade com a divulgação por meio da internet.

Além disso, Bim (2014) adverte que a audiência pública é instrumento cuja principal função é promover maior participação e complementar a fase de comentários existente no processo de licenciamento ambiental, indo além, ao esclarecer que o instrumento tem caráter secundário, e possui por escopo o reforço da participação já existente no processo de licenciamento. Nesse sentido, o autor continua:

"O constituinte não reconheceu como função da audiência pública a divulgação do conteúdo do Estudo de Impacto Ambiental e do Relatório de Impacto ao Meio Ambiente, atribuindo essa função a publicidade. A função prevista na Assembleia 
Constituinte para audiências públicas era a de discussão em um local onde o EIA pudesse passar pela avaliação pública. Esse reconhecimento reforça que a suposta função informativa prevista na Resolução CONAMA 09/1987 é endógena ou apenas é um aspecto sociológico, uma vez que sem respaldo na história legislativa. Na verdade, a Resolução CONAMA 09/1987 copiou a lei francesa Bouchardeau (Lei 83-630 de 12.07.1983), que era expressa em prever como função da enquete pública a (i) informação ao público e (ii) coleta de seus depoimentos, sugestões e críticas. Fez-se uma transposição acrítica do instituto do direito francês, para que tinha expressa base legal, para, do nada, criar uma função fora do eixo para as audiências públicas no Brasil, por ato infralegal e sem respaldo de qualquer tradição jurídica nacional" (BIM, 2014, p. 81-82).

No entanto, apesar de restar clara a finalidade geral das audiências públicas na promoção de debates, no que tange ao processo de licenciamento ambiental existem inúmeros questionamentos quanto à eficácia do referido instrumento em alcançar seu objetivo. Alonso \& Costa (2004) indicam que as audiências públicas tendem a expressar mais as opiniões da sociedade civil organizada do que as dos grupos sociais diretamente atingidos pela atividade ou empreendimento a ser licenciada. Holmes \& Scoones (2000) avaliam os mecanismos deliberativos em questões ambientais usados no hemisfério norte e hemisfério sul, identificando que a motivação para participar dos processos deliberativos variam entre os grupos organizados e os cidadãos comuns, já que enquanto os primeiros possuem opiniões definidas previamente, os outros apresentam dificuldades na construção e apresentação de seus argumentos. Entretanto, em defesa dos processos participativos, Antunes (2005) afirma que muitas das questões suscitadas em juízo, relacionadas ao licenciamento ambiental, poderiam ser resolvidas em sede administrativa caso os procedimentos fossem mais abertos à participação comunitária desde o seu início.

\section{ANÁliSE EMPÍRICA DAS AUDIÊNCIAS PÚBLICAS NOS PROCESSOS DE LICENCIAMENTO AMBIENTAL}

Da compilação e análise dos dados coletados no levantamento documental da pesquisa, foi possível identificar o quantitativo de audiências públicas realizadas pelo Instituto Estadual do Ambiente - INEA do Estado do Rio de Janeiro, no âmbito de processos de licenciamento ambiental, durante o lapso temporal de 2013 a 2016. O recorte espacial desta pesquisa se justifica tanto pelas circunstâncias históricas da gênese do licenciamento ambiental no ordenamento brasileiro, que teve o estado do Rio de Janeiro como seu percursor, como também poderá ser justificado pela necessidade de compreensão da conjuntura participativa no âmbito do licenciamento ambiental carioca. Por outro lado, o recorte temporal 
deste trabalho foi elaborado no intuito de abranger o lapso temporal correspondente ao momento posterior à elaboração da Resolução Conema ${ }^{\circ}{ }^{\circ}$ 35/2011 e a ocasião em que o INEA passou a realizar a transcrição de inteiro teor das audiências efetivadas.

Assim, no ano de 2013 foram realizadas 10 audiências públicas; ao passo que em 2014, esse quantitativo aumentou para 11; em 2015 se verificou uma leve queda para 10 Audiências Públicas realizadas e; em 2016, apenas 1 (uma) Audiência Pública foi realizada no âmbito do licenciamento ambiental de atividades ou empreendimentos no Estado do Rio de Janeiro.
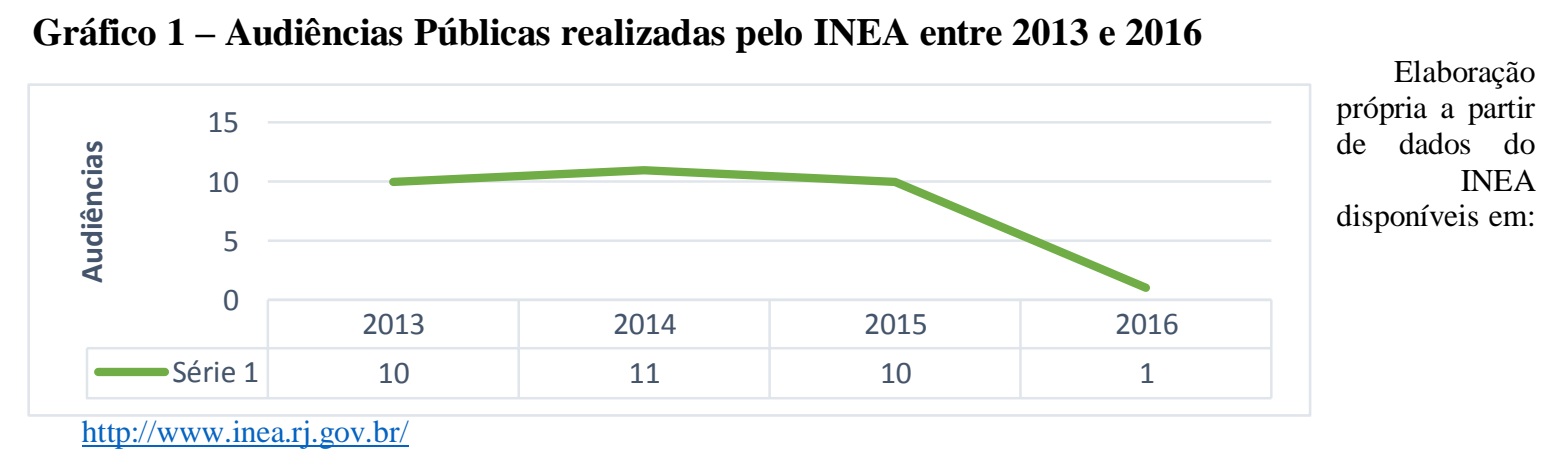

Ademais, apesar o Decreto Estadual 44.820/2014 especificar mais de 30 grupos que diferenciam e classificam as atividades e empreendimentos que estão sujeitas ao licenciamento ambiental estadual atualmente, da análise e compilação dos dados coletados das Audiências Públicas realizadas entre 2013 e 2016, houve a incidência de apenas 05 grupos de atividades e empreendimentos. O grupo de maior incidência de realização de audiências públicas no âmbito do licenciamento ambiental corresponde o de atividades e empreendimentos da Construção Civil, com o quantitativo de 21 audiências realizadas. Em seguida, os grupos de Serviços de utilidade pública e de Unidades auxiliares de apoio industrial e Serviços industriais aparecem empatados, cada um com 04 audiências públicas realizadas. O grupo de Extração de minerais realizou 03 audiências públicas entre o lapso temporal de 2013 e 2016; e por fim, o grupo de Produção de minerais não metálicos realizou 01audiência pública no mesmo período.

Objetivando demonstrar a dinâmica da participação nos debates travados nas audiências concretizadas no âmbito de licenciamento ambiental foram destacados a 
distribuição quantitativa das manifestações dos participantes das audiências públicas. Este estudo foi realizado na tentativa de gerar dados para a identificação da existência ou não da promoção da participação da sociedade nos processos de licenciamento ambiental através das audiências públicas.

Para o estudo em questão, foi considerada como manifestação toda pronunciação incluída nas transcrições de inteiro teor publicadas pelo INEA e realizada durante as audiências públicas em estudo, que tratassem da condução dos debates, emissão de perguntas, comentários, críticas; sugestões e opiniões.

Para a presente análise, foi consultado o registro documental escrito dos debates promovidos, que consistiram principalmente em atas e transcrições de inteiro teor de 32 audiências públicas promovidas no contexto em estudo. Os documentos consultados foram obtidos no sítio oficial do INEA-RJ.

Em 2011 foi editada a Resolução no 35 do Conselho Estadual do Meio Ambiente do Estado do Rio de Janeiro - Conema, que, dentre outras questões, indica o registro do conteúdo dos debates orais das audiências públicas do licenciamento ambiental. Assim, o INEA registra o conteúdo dos debates orais de forma escrita e os disponibiliza na internet, sendo todos integralmente transcritos em atas das audiências públicas, que consignavam o local do evento, a data de sua realização, identificação dos participantes e suas falas. É ainda interessante destacar que também são disponibilizados para consulta online os Estudos de Impacto Ambiental e seus respectivos Relatórios, filmagem das audiências públicas em arquivo digital de vídeo e áudio.

Ademais, no que diz respeito aos horários de promoção e duração das audiências públicas analisadas, foi observada certa regularidade quanto aos dois quesitos. Todos os diálogos sobre o licenciamento ambiental de obras e empreendimentos no Estado do Rio de Janeiro ocorreram no turno da noite, com início entre as dezenove horas e dezenove horas e quarenta e sete minutos. Em regra, os eventos tiveram duração média de três horas, o que ocorreu em 26 audiências públicas. No entanto, foram observados dois contextos em que ocorreram exceções à regra de duração dos eventos, onde em três audiências a duração foi de uma hora e quarenta e cinco minutos e outras três audiências tiveram duração superior a cinco horas, sendo uma de cinco horas e trinta minutos; outra de cinco horas cinquenta minutos e a 
seguinte de seis horas e cinquenta minutos. Das audiências que tiveram duração inferior à média de três horas, duas tratavam da instalação de aterro sanitário para resíduos sólidos e outra da atividade de extração de areia. Por sua vez, das audiências que tiveram duração superior à média, todas tratavam de empreendimentos para instalação de terminal portuário.

Quanto aos locais em que as audiências públicas foram realizadas, notou-se uma variação de ambientes utilizados para receber os participantes, sendo tanto de instalações públicas quanto privadas. Assim, no contexto em estudo os locais para realização dos debates

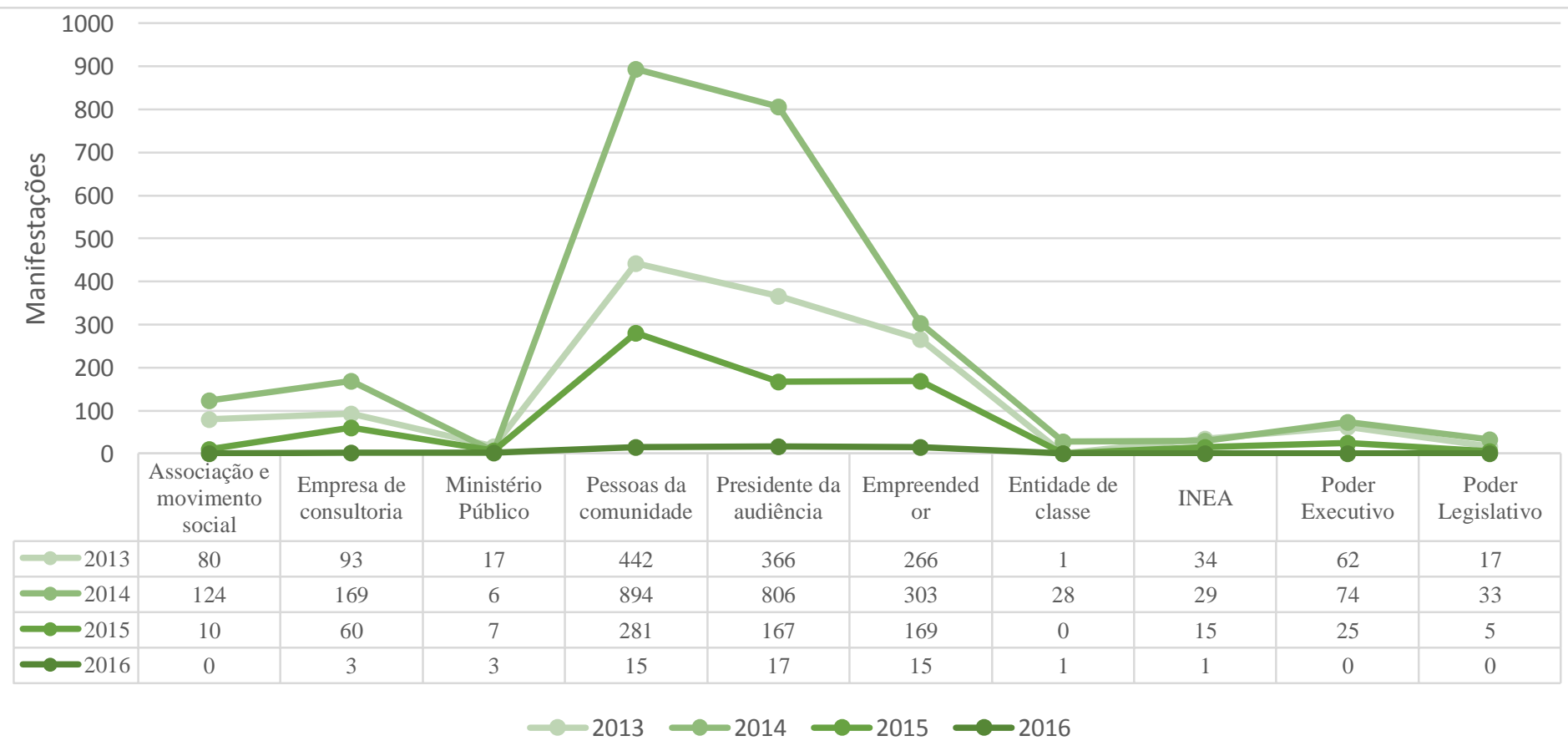

variaram entre colégios públicos; auditório de hotéis; clubes; salões de festa; estádios municipais e; câmaras comunitárias.

Ademais, a partir do levantamento quantitativo, foi possível identificar a dinâmica de participação nas audiências públicas realizadas em licenciamento ambiental do estado do Rio de Janeiro entre os anos de 2013 e 2016.

Ao todo, foram identificadas 4517 (quatro mil quinhentas e dezessete) manifestações dos participantes das audiências públicas para licenciamento ambiental entre 2013 e 2016, distribuídas da seguinte forma:

Gráfico 15 - Distribuição das manifestações dos participantes das audiências públicas entre 2013 e 2016 Elaboração própria a partir de dados do INEA disponíveis em: http://www.inea.ri.gov.br/ 
Então, é observado que, entre 2013 e 2016, houve 4517 manifestações de participantes das audiências públicas referentes a licenciamento ambiental no estado do Rio de Janeiro, sendo 1632 de pessoas da comunidade; 1356 do presidente da audiência; 753 do representante do empreendedor; 325 da empresa de consultoria; 224 de associações e movimentos sociais; 161 de representantes do Poder Executivo; 133 de representantes do Poder Legislativo; 78 do representante do INEA; 33 do Ministério Público e; 30 de entidades de classe.

$\mathrm{O}$ ano em que houve maior número de manifestações de pessoas da comunidade, associações e movimentos sociais foi 2014, seguido de 2013. Em 2015 é possível observar uma queda considerável da participação de associações e movimentos sociais nos debates travados nas audiências públicas, e em 2016, por sua vez, não houve qualquer manifestação destes participantes. No que tange às pessoas da comunidade, por sua vez, também houve considerável queda no número de manifestações durante os anos de 2015 e 2016. No entanto, devemos observar que os dados do ano de 2016 podem representar baixo índice de participação em relação aos outros anos devido ao fato de ter sido realizada apenas uma audiência pública. Em 2015, no entanto, de fato os dados devem representar baixo índice de participação de pessoas da comunidade, associações e movimentos sociais quando relacionados aos anos anteriores, posto que a média de realização de audiências públicas não foi consideravelmente alterada.

De maneira geral, entre 2013 e 2016, do total de 4517 manifestações em audiências públicas para licenciamento ambiental no estado do Rio de Janeiro, em média, 36\% corresponderam às manifestações de pessoas da comunidade; enquanto $30 \%$ às do presidente da audiência; $16 \%$ do representante do empreendedor; $7 \%$ da empresa de consultoria; $5 \%$ de associações e movimentos sociais; $4 \%$ de representantes do Poder Executivo; 3\% de representantes do Poder Legislativo; $2 \%$ do representante do INEA; 0,5\% de entidades de classe e; 0,5\% do Ministério Público:

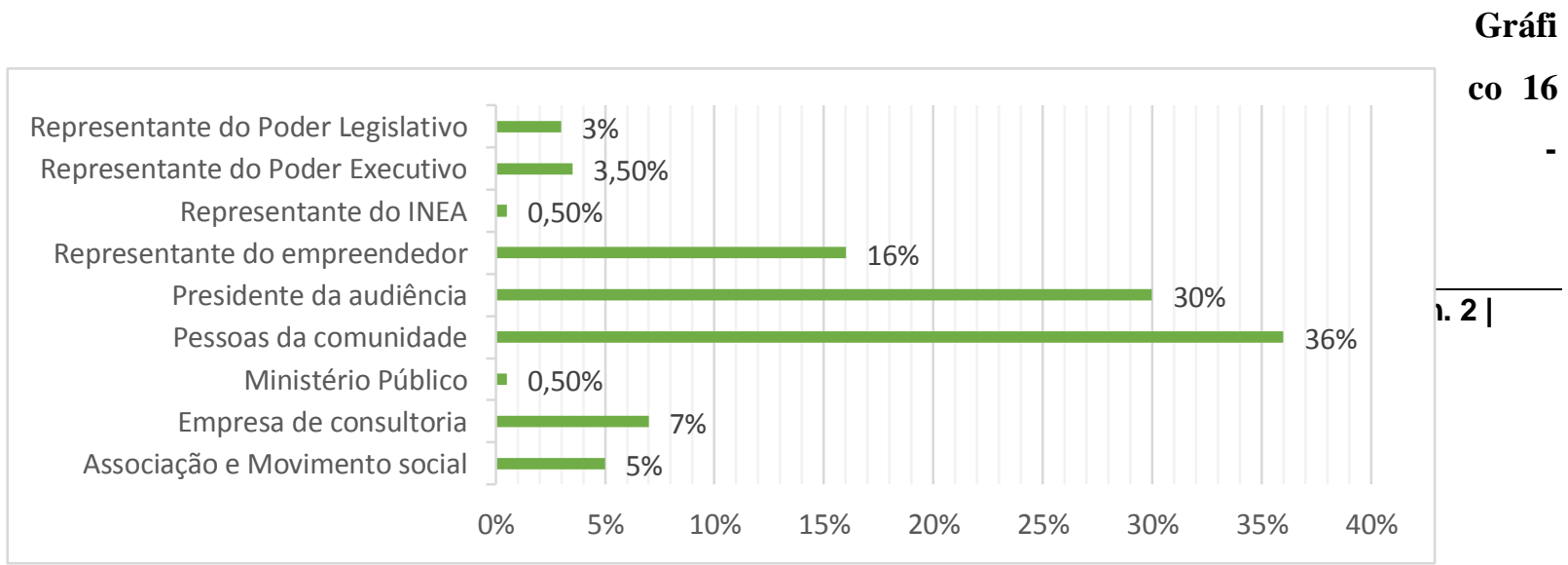




\section{Porcentagem das manifestações dos participantes entre 2013 e 2016}

Elaboração própria a partir de dados do INEA disponíveis em: http://www.inea.rj.gov.br/

É lícito relembrar que Bim (2014) assevera que a audiência pública é instrumento cuja principal função é a promoção de maior participação social. Conforme se verificou pela análise dos dados, as audiências públicas em licenciamento ambiental no estado do Rio de Janeiro contaram com ativa participação de pessoas comuns das comunidades e com a presença e atuação de associações e movimentos sociais. Assim, pela análise geral dos dados, podemos constatar que este instrumento tem cumprindo a função de promoção de maior participação dos cidadãos nos processos de licenciamento ambiental.

Entretanto, quando analisamos os anos separadamente e de maneira comparativa, observamos um índice mais alto de participação de pessoas da comunidade, associações e movimentos sociais durante os anos 2013 e 2014, e uma queda considerável dessa participação em 2015 e 2016. Além disso, em 2016 houve também queda drástica no número de audiências públicas realizadas pelo INEA.

Além disso, não é possível identificar que se concretizou empiricamente a indicação de Alonso \& Costa (2004), ao afirmar que as audiências públicas tendem a expressar mais as opiniões da sociedade civil organizada do que as dos grupos sociais diretamente atingidos pela atividade ou empreendimento a ser licenciado, posto que as pessoas da comunidade apresentaram o grau mais elevado de manifestações em quase todas as audiências públicas realizadas.

A atuação ministerial, por sua vez, desempenha papel importante na morfologia social no qual se inserem os conflitos em torno do uso do meio ambiente no Estado do Rio de Janeiro (SOARES, 2010). No processo de licenciamento ambiental, o parquet atua também enquanto representante da sociedade (Ferreira, 2015, p. 152), ao lado dos cidadãos e das organizações não governamentais. Como defensor da ordem jurídica, da sociedade e dos atos da Administração Pública, desempenha função extremamente relevante da defesa dos direitos no plano coletivo, inclusive do direito fundamental ao ambiente ecologicamente equilibrado. Assim, para Moraes (2013), o Ministério Público se constitui em um elo entre os anseios da sociedade e os deveres e possibilidades do Estado. 
Entretanto, pela presente análise foi verificado que a atuação do Ministério Público não tem sido efetiva no que tange às audiências públicas em licenciamento ambiental no Estado do Rio de Janeiro, posto que o mesmo não se fez presente na maioria dos debates realizados e quando presente, se reservou a realizar poucas manifestações.

O presidente da audiência pública fica a cargo da responsabilidade do controle e condução os debates, além da leitura das perguntas escritas enviadas pelo público participante das audiências. Dessa forma, é compreensível que este tenha apresentado um alto índice de manifestações. Além disso, conforme assevera Oliveira (2010), as audiências públicas em licenciamento ambiental possuem duplo papel informativo, propiciando aos cidadãos a possibilidade de manifestações e a obtenção de informações, caracterizando um ambiente onde ele poderá ouvir e ser ouvido. Assim, não seria correto afirmar que as audiências públicas não estejam desempenhando corretamente seu papel principal apenas com base nos dados que refletem um alto índice de manifestações de autoridades, a exemplo do presidente da audiência. Seria necessário, para tanto, uma análise mais complexa e qualitativa desse instrumento de participação popular.

Nesse sentido, o alto índice de manifestações do presidente da audiência pública não nos leva a inferir que as audiências públicas não estejam cumprindo sua função de promoção de participação cidadã, posto que houve maior participação de pessoas da comunidade e, além disso, a responsabilidade pela condução dos debates obriga o presidente a efetuar muitas manifestações no decorrer dessas audiências.

Já o representante do empreendedor e a empresa de consultoria atuam tanto na fase de apresentação do empreendimento ou atividade a ser licenciada, quanto na fase dos debates. Inicialmente, o representante do empreendedor fica a cargo de apresentar a empresa responsável pelo projeto, assim como sua proposta, justificativa e objetivos do empreendimento ou atividade e, de maneira mais sucinta, apresentar o prognóstico ambiental da área de a ser utilizada, os impactos ambientais previstos e medidas mitigatórias e compensatórias. Terminada a fala do empreendedor, é a vez da empresa de consultoria proceder com a apresentação do Estudo de Impacto Ambiental e seu Relatório. Essa apresentação é realizada de maneira didática, possibilitando que o público presente possa compreender o estudo e formular questionamentos sobre o mesmo. 
Passada a fase de apresentações e após um breve intervalo, é iniciada a fase de debates, onde são lidas as perguntas escritas enviadas pelos participantes e é dada oportunidade de fala aos mesmos. Na grande maioria das vezes as perguntas são direcionadas ao representante do empreendedor ou à empresa de consultoria, que mais uma vez podem se manifestar, já que ficam responsáveis por sanar as dúvidas do público acerca do empreendimento ou atividade passível de licenciamento.

Assim, apesar de possuir dois momentos de fala, tanto da fase de apresentação quanto na fase dos debates, o representante do empreendedor e a empresa de consultoria não apresentaram os maiores índices de manifestações, restando com $16 \%$ e $7 \%$ respectivamente, com o $3^{\circ}$ e $4^{\circ}$ posto de maiores manifestantes, estando atrás das pessoas da comunidade $(36 \%)$ e do presidente da audiência (30\%).

Como a audiência pública em licenciamento ambiental é caracterizada pela bilateralidade, onde os cidadãos podem realizar suas manifestações e ouvir informações acerca do licenciamento ambiental, seria compreensível se tanto o representante do empreendedor, como a empresa de consultoria e as pessoas da comunidade possuíssem níveis de manifestação parecidos. No entanto, isto não ocorre, e poderá ser justificado pelo fato de que algumas das manifestações de pessoas da comunidade não são preenchidas por uma dúvida ou questionamento, mas simplesmente por uma opinião. Além disso, em segundo plano, muitos dos questionamentos das pessoas da comunidade tratam da mesma temática e são incluídas em blocos de perguntas seguidas e respondidas em uma só manifestação pelos representantes do empreendedor ou pela empresa de consultoria.

Os representantes do Poder Executivo e Legislativo se fizeram presentes em quase todas as audiências públicas estudadas, apresentando algum grau de participação. Tal fato pode ser positivo para as audiências, posto que gera um incremento de informações e propicia uma abertura de canal para as reinvindicações das pessoas da comunidade, associações e movimentos sociais, já que estes poderão incluir em suas manifestações algumas temáticas que ultrapassam o processo de licenciamento ambiental.

As entidades de classe apresentaram um baixo grau de manifestações, justificado pelo fato de não estar presente na maioria das audiências públicas realizadas. O representante do INEA, por sua vez, também apresentou baixo grau de manifestações, que poderá ser 
justificado pelo fato de o mesmo ficar responsável apenas pela apresentação didática do processo e etapas do licenciamento ambiental, o que ocorre na fase das apresentações.

\section{CONSIDERAÇÕES FINAIS}

A democracia participativa se concretiza através do oferecimento de oportunidades aos cidadãos para que participem da tomada de decisão que tenha relevância coletiva. Assim, os instrumentos idealizados a partir da noção da democracia participativa seriam definidos como um fórum aberto ao exercício livre e desinteressado do debate entre cidadãos que são igualmente livres e estão plenamente informados e espontaneamente envolvidos na deliberação de questões que se referem a determinada comunidade.

A audiência pública surgiu enquanto instrumento que tem por escopo promover o aumento da participação dos cidadãos nas decisões do Estado. No âmbito administrativo podem ser encontrados diversos exemplos de utilização deste novo instrumento para promoção do aprofundamento da democracia brasileira, mas é na seara do licenciamento ambiental em que esta tende a unir os ideais da cidadania e do desenvolvimento sustentável.

Para que a audiência pública esteja em concordância com o que preceitua a teoria da democracia participativa, é necessário que ela seja estruturada com o objetivo claro de promover a participação dos cidadãos interessados, seja através de opiniões, questionamentos ou críticas, tanto de forma oral quanto escrita. Assim, no que diz respeito ao que ordena tanto o regime geral das audiências públicas (Lei 9.784/1999), quanto à Resolução Conema $n^{\circ}$ $35 / 2011$, temos que estes instrumentos participativos possuem enquanto objetivo normativo a promoção debates; o fomento e permissão da participação pública; e dar transparência e maior publicidade ao processo de licenciamento ambiental.

Além disso, a partir do estudo empírico realizado neste trabalho foi identificado que, durante os anos de 2013 e 2016, foram realizadas 32 audiências públicas em licenciamento ambiental pelo Estado do Rio de Janeiro. Em média, os anos de 2013, 2014 e 2015 apresentaram índices parecidos de promoção das audiências, ao contrário do que foi observado em 2016, quando foi realizada apenas 1 audiência pública.

A partir desse resultado, é possível vislumbrar que o cenário econômico do Estado refletiu de maneira compreensiva no índice de realização de audiências públicas em 
licenciamento ambiental, posto que o Estado começou a demonstrar sinais de crise em meados de 2015 para o ano de 2016. Assim, os processos de expansão da participação e melhoria de legitimação dos processos de decisão estatais tendem a sofrer abalos diante do cenário econômico de anormalidade.

Não obstante, em segundo momento, foi analisado que contrabalanceando o grau de participação através de manifestações das pessoas presentes nas audiências públicas, houve grande atividade de agentes da sociedade, tais quais pessoas da comunidade, e alguma atividade de grupos sociais organizados, como associações e movimentos sociais. Os agentes mais ativos nas audiências públicas foram as pessoas da comunidade, que apresentaram questionamentos e opiniões tanto de forma oral quanto escrita. Assim, inicialmente, é possível vislumbrar que os debates analisados ocorreram dentro da arena deliberativa tendo o instrumento em estudo conseguido expandir a participação no processo de decisão em licenciamento ambiental no estado do Rio de Janeiro.

Entretanto, não é possível esquecer que de acordo com a noção de democracia participativa, este instrumento deve, teoricamente, promover um fórum aberto ao exercício livre e desinteressado do debate entre cidadãos que são igualmente livres e estão plenamente informados e espontaneamente envolvidos na deliberação de questões que se referem a determinada comunidade.

Ao relacionar a noção de democracia participativa para os instrumentos de participação cidadã com o conceito de audiência pública oferecido pela Resolução Conema $35 / 2011$, que preceitua a sua destinação de fomentar e permitir a participação pública das comunidades interessadas e afetadas pelos impactos ambientais dos empreendimentos e atividades efetiva ou potencialmente poluidores, temos que as audiências públicas cumprem sua função quando promovem ambientes abertos ao exercício do debate entre cidadãos igualmente livres, plenamente informados, e envolvidos na deliberação sobre questões que se relacionam as comunidades interessadas ou afetadas pelos impactos ambientais do empreendimento ou atividade potencialmente poluidora.

Outrossim, a partir destes dois conceitos podem ser vislumbrados dois requisitos básicos para que as audiências públicas cumpram seu papel de promotora da participação cidadão nas questões ambientais: em primeiro plano ela deve ser capaz de prover a 
participação no processo de licenciamento; e em segundo plano os cidadãos participantes devem ser informados e envolvidos ou interessados pelas questões ambientais relacionadas ao empreendimento ou atividade em debate.

Analisando os resultados obtidos pelo estudo desenvolvido no presente trabalho, é possível tirar algumas conclusões iniciais sobre a dinâmica da participação nas audiências públicas em licenciamento ambiental.

Primeiramente, este estudo demonstrou que o desenho institucional das audiências públicas é capaz de atingir um dos objetivos normativos, posto que ele foi capaz de fomentar e permitir a participação pública das comunidades interessadas e afetadas pelos impactos ambientais dos empreendimentos e atividades efetiva ou potencialmente poluidores.

Entretanto, a partir dos dados analisados, não é possível afirmar que os cidadãos participantes são plenamente informados acerca das questões ambientais relacionadas ao empreendimento ou atividade em debate. Para tanto, seria necessária a realização de um estudo qualiquantitativo que avaliasse as falas e temáticas abordadas por cada participante das audiências públicas, para, assim, se inferir acerca da adequação do nível informacional dessas deliberações.

Um outro fator relevante observado nesta pesquisa, e que também está relacionado à participação cidadã, consistiu na pouca ou mesmo na falta de atuação do Ministério Público durante as audiências realizadas, posto que o parquet apresentou um dos índices mais baixos de manifestações. Atuando como defensor dos interesses sociais, o Ministério Público deve estar presente do processo de licenciamento como elemento de controle, além de representar a sociedade civil, que igualmente participa do processo. Com base no que preceitua Ferreira (2015), é certo que a atuação ministerial "supre a falta de atuação da sociedade civil, muitas vezes ainda incipiente". Entretanto, foi observado, a partir deste trabalho, que o Parquet tanto estadual quanto federal tem pouca ou nenhuma atuação durante a realização dos debates para licenciamento ambiental, enquanto a sociedade demonstrou uma performance mais ativa e presente, ainda que seja questionável em partes a qualidade desta participação.

Esta conjuntura poderá se demonstrar prejudicial ao desenvolvimento da audiência pública enquanto instrumento promotor de uma participação eficaz da sociedade no processo de licenciamento, posto que a sociedade civil brasileira ainda está desenvolvendo a cultura 
participativa e, em alguns casos, é fraca e desorganizada, se mostrando incapaz de defender seus interesses fundamentais, resultado na fundamental proposta de atuação do Ministério Público para intervir na relação Estado/cidadão em defesa dos interesses desse último.

De toda forma, é inegável reconhecer que as audiências públicas se constituem em um dos instrumentos potencialmente inovadores da democracia representativa brasileira, posto que é utilizada nas diversas esferas de poder do Estado. Além disso, se constitui em uma das maneiras de promover a cidadania para o desenvolvimento sustentável que o Brasil necessita, já que permite que os cidadãos intervenham de alguma forma nas questões administrativas, influenciando e se informando sobre a tomada de decisão ambiental que impacta diretamente suas vidas.

Sendo assim, é de extrema importância que sejam realizadas novas avaliações empíricas acerca da utilização desse instrumento pela administração pública brasileira, para que seja possível identificar tanto seus benefícios quanto suas falhas, na tentativa de qualificar a cultura participativa da sociedade no que diz respeito às questões socioambientais.

\section{REFERÊNCIAS}

ALONSO, A.; COSTA, V. Dinâmica da participação em questões ambientais: uma análise das audiências públicas para licenciamento ambiental do Rodoanel. In: COELHO, V. S.; NOBRE, M. (orgs.) Participação e Deliberação: teoria democrática e experiências institucionais no Brasil contemporâneo. Rio de Janeiro: 34 Ltda., 2004.

ANTUNES, P. B Política Nacional do Meio Ambiente (PNMA): comentários à Lei 6.938 de 31 de agosto de 1981. Rio de Janeiro: Lúmen Juris, 2005.

ACSERALD, H. LEROY, J. P. Novas premissas da Sustentabilidade Democrática. Cadernos de Debate 1, Projeto Brasil Sustentável e Democrático, FASE, RJ, 1999, pp. 70.

BACKeS, A. L; AZEVEDO, D. B; ARAÚJO, J. C. Audiência Pública na Assembleia Constituinte: a sociedade na tribuna. Brasília: Câmara dos Deputados, Edições Câmara, 2009.

BIM, E. F. Audiências Públicas. $1^{\text {a }}$ ed. São Paulo: Revista dos Tribunais, 2014

BIM, E. F. Licenciamento Ambiental. 3 ${ }^{\mathrm{a}}$ ed. Rio de Janeiro: Lumen Juris, 2016.

CABRAL, A. Os efeitos processuais da audiência pública. Boletim de Direito Administrativo. Vol 22. N. 7. P. 789-800. Jul. 2006.

DI PIETRO, M. S. Z. Direito Administrativo. 31 ed. São Paulo: Atlas, 2018.

DOMINGOS, H. R. A.; LANCHOTTI, A. O.; DIZ, J. B. M. Audiências Públicas:

Instrumento de participação popular na tomada de decisão em meio ambiente. Belo Horizonte: Arraes, 2016. 
FERRAZ, C. C. O. Participação social na elaboração de normas das agências reguladoras no Brasil e nos Estados Unidos da América do Norte. In: DI PIETRO, M. S. Z. Direito regulatório: temas polêmicos. 2 ed. Belo Horizonte: Forum, 2004.

FIORILlO, C. A. P. Curso de Direito Ambiental. 17 ed. São Paulo: Editora Saraiva, 2017.

HOLMES. T. SCOONES. I. Participatory Environmental Policy Processes: Experiences from North and South. Working Paper 113, IDS (Institute of Devolepment Studies), University of Sussex, UK, 2000.

MACHADO, P. A. L. Direito Ambiental brasileiro. 24ª ed. São Paulo: Editora Malheiros, 2016.

MARRARA, T. Da instrução. In: NOHARA, I. P; MARRARA, T. Processo Administrativo: Lei 9.784/1999 comentada. São Paulo: Atlas, 2009.

MELO, C. A. Audiência Pública na função administrativa. Belo Horizonte: Arraes, 2016.

MOREIRA NETO, D. F. Direito de participação política: legislativa, administrativa, judicial. Rio de Janeiro: Renovar, 1992.

NOHARA, I. P. Participação popular no processo administrativo: consulta, audiência pública e outros meios de interlocução comunitária na gestão democrática dos interesses públicos. In: NOHARA, I. P; MORAES FILHO, M. A. Processo administrativo: temas polêmicos da Lei 9.784/1999. São Paulo: Atlas, 2011.

OLIVEIRA, G. J. Direito Administrativo democrático. Belo Horizonte: Fórum, 2010.

SILVA, A. O. S. Participação popular na administração pública: audiências públicas. Dissertação de mestrado, São Paulo, PUC, 2009. 